\title{
THE USE OF INNOVATIVE METHODS IN TEACHING SOCIAL SCIENCES
}

\author{
Natalia Ageeva ${ }^{1 *}$, Tatiana Ivanova ${ }^{2}$, Rustem Idrisov ${ }^{3}$, Marina Krasnova ${ }^{4}$, Oleg \\ Shirokov ${ }^{5}$, Marina Shirokova ${ }^{6}$
}

${ }^{1} \mathrm{Ph}$. D., associate professor of the Department of foreign history and culture, I. N. Ulianov Chuvash

State University, Moskovsky Ave., 15, Cheboksary, Chuvash Republic, Russia, 428015, Russia email address: nageeva@mail.ru

${ }^{2}$ Doctor of History, Professor of the Department of foreign history and culture, I. N. Ulianov Chuvash State University, Moskovsky Ave., 15, Cheboksary, Chuvash Republic, Russia, 428015, Russia email address: tivanovan@mail.ru

${ }^{3} \mathrm{Ph}$. D., associate professor of the Department of foreign history and culture, I. N. Ulianov Chuvash

State University, Moskovsky Ave., 15, Cheboksary, Chuvash Republic, Russia, 428015, Russia email address: ridrisov21@mail.ru

${ }^{4} \mathrm{Ph}$. D., associate professor of the Department of foreign history and culture, I. N. Ulianov Chuvash

State University, Moskovsky Ave., 15, Cheboksary, Chuvash Republic, Russia, 428015, Russia email address: makrasnova@mail.ru

${ }^{5}$ Doctor of History, Professor of the Department of foreign history and culture, I. N. Ulianov Chuvash State University, Moskovsky Ave., 15, Cheboksary, Chuvash Republic, Russia, 428015, Russia email address: oleg shirokov1970@mail.ru

${ }^{6} \mathrm{Ph}$. D., associate professor of the Department of foreign history and culture, I. N. Ulianov Chuvash State University, Moskovsky Ave., 15, Cheboksary, Chuvash Republic, Russia, 428015, Russia email address: mlemaeva@mail.ru

${ }^{*}$ Corresponding Author

\begin{abstract}
The development of methods of teaching social sciences in the higher education system at the present stage is of particular relevance. This is due to both the complication of the social structure itself and the increase in knowledge in this area, the improvement of its methodology and methodological searches. The aim of the research proposed by the authors is to generalize the practical experience of teaching social disciplines. The practical significance of the proposed study is due to the effectiveness of the results of teaching, modernized directly in the course of the reform of the higher education system in Russia. As research materials, the authors used the results of their own developments, created in the course of repeated approbation of innovative teaching methods and forms of education. We consider the basic principles of studying the social sciences in modern higher education to be continuity, succession, intergrability and openness of education, as well as its creative, research nature. In the practice of students' educational activities, these principles are embodied in active forms of learning and the use of modern online technologies, which today has acquired particular relevance.
\end{abstract}

Keywords: social sciences, teaching methods, innovative technologies, higher education system. 


\section{INTRODUCTION}

Social science teaching remains an essential element in higher education in every profile in every country. Reflecting current trends and new challenges, it is constantly evolving, increasing its methodological and methodical bases. It should be noted that in the context of reforming the systems of higher education, the relevance of academic disciplines of a social profile is not only preserved, but also increasing. Together with it, the methods of teaching these disciplines are being updated. This happens for a number of reasons.

The first of these, which we are all witnessing, is the continuous complication of the social structure. As the consequences of globalization and the next stage of the scientific and technological revolution spread, it can be stated that this process has acquired an "avalanche-like" character. In the modern world, we observe a constant increase in new categories of social factors, the emergence of previously unknown professions and the loss of the former prestige and significance by othernew specialtieswhich hasalso emerged relatively recently and a sharp change in social statuses, their hybridization and the allocation of new internal gradations. The modern practice of work in a higher educational institution shows, for example, how rapidly the contingent of students is changing in terms of the level of initial knowledge, applied skills, their personal goals and life strategies. This far from complete list of signs of the complication of the social structure requires its own understanding, systematization, and the development of appropriate categories and approaches. As a result, the requirements for the teaching methods of the social sciences are changing.

The second reason is the ever-increasing knowledge of the social sciences. This, in turn, causes the subsequent development of the methodology of science and the emergence of new research methods. Postmodern tendencies in scientific methodology currently allow to significantly expand the individual approaches of social scientists to the problems of history, political science, sociology, and cultural studies. In the methodology of teaching the social sciences, this is reflected in the continuity, succession, integrability and openness of education, as well as its creative and research nature. Practice-oriented training based on active forms is becoming more and more in demand. The noticeably changed technical level of the educational process and the objectively emerging need for accelerated mastering of online technologies and various kinds of the Internet practices should also be added to this.

Such a broad understanding of the relevance of social knowledge and the methods of studying it in higher education allows us to single out the main goal of our research. It is the identification of the most significant, in the opinion of the authors, innovative methods of teaching social sciences in a modern higher educational institution and the development of appropriate methods for organizing and conducting training sessions. It is possible to achieve such a goal by solving a number of key tasks: substantiation of the choice of teaching methods that have received many years of approbation in the practical work of the authors of the article; study and generalization of the results of this work, expressed in the development of specific methodological guidelines; proposing recommendations for further improving the effectiveness of the described methods and their development in the pedagogical practice of higher education.

\section{LITERATURE REVIEW}

The problems that have arisen in the teaching of the social sciences have become the subject of research by a number of specialists whose papers haverecently been published. They all agree that this topic is the subject of a constant search for a large number of practicing teachers who face the need to rapidly update the methodological and methodical bases of teaching social disciplines both in higher education and in secondary education. However, the shortage of works of a generalizing plan that can indicate a certain global path of development of this direction of pedagogical thought remains palpable. We see an even greater shortage in the category of works with scientific predictive qualities. Meanwhile, an analysis of the current state of the teaching methods of social sciences should predict its further direction of development, taking into account the changes already taking place in society. Unfortunately, the latter aspect of research remains the subject of popular futurism, most of which has nothing to do with science.

When studying papers on the development of social science teaching methodology, one can notice a significant change in approaches, even over a relatively short period of time. In 2005, for example, an interesting article was published $b$ William Paterson. Professor at New Jersey University, and Thomas Fallas and Johannes Nime, Professors at Western Washington University, revealing the possibilities of using historiographic texts in the training of history teachers. [5] Researchers highly appreciate the new opportunities in the professional training of historians, which appear precisely as a result of the study of historiographic texts containing the author's interpretations of historical events and phenomena. Without diminishing the significance of the research carried out by our American colleagues, we note that their methodology is still based on the traditional analysis of the text, albeit historiographic, not historical. 
In 2011, a group of Israeli researchers from the Universities of Haifa and Jerusalem described the results of an experiment they had conducted with students from different ethnic groups writing an essay on the topic "Could they do it differently?" [9] In this case, the now widespread methodology of project activities has created an additional acuteness of the historical dispute precisely because of the ethnicity of the students.

The theoretical results of the experiment were summed up by the head of the research group, Professor of Philosophy at the University of Haifa Goldberg Zafrir, in an article published in 2013 "It's in my veins": identity and disciplinary practice in students' discussions of historical problem. "[8] The author notes that the described experiment is actually part of a global effort to develop history teaching in Western democracies, a method used by educators in Northern Ireland, for example, to overcome fears of emotional excesses among educators themselves in multicultural settings. [8, 36]

A broader generalizing study is the study of the University of Southampton research assistants $\mathrm{S}$. Lewtwait and M. Nind "Methodology for teaching research in the social sciences: expert views on pedagogy and practice", published in 2016. These scholars drew attention to a significant gap in the study of teaching Social Sciences methodology: "Most authors report a lack of discussion, cross-citation in the literature, dialogue in disciplinary contexts, and significant empirical research." $[14,413]$ They tried to fill it with the use of the dialogical method of expert panels with the involvement of international experts.

A similar generalization of the national methodological experience in 2017 was carried out by the Dutch professors B. Vansink, S. Ackermann and T. Wubbels. [18] In this case, they were interested in finding out the possibilities of using the interpretational approach by 15 highly qualified history teachers when considering certain topics. Researchers note, among other things, the importance of using this approach as a way to overcome closed narratives containing exclusively "objective facts". The flaw in this traditional method of "memorizing" history under the guidance of a teacher is that students do not develop the research skill of alternative ways of cognition.

The article by a group of researchers from the University of Amsterdam, "Teaching Historical Thinking and Reasoning: Building Observation Instruments", published in 2018, is devoted to the same topic of overcoming the shortcomings of traditional history teaching. [7] The authors' conclusions are based on observing a series of history lessons in Iceland and the Netherlands and are in the need to abandon traditional methods in favor of the development of historical thinking. This approach was called by researchers "making history" in contrast to the so-called "subject history". Without diminishing the importance of traditional approaches in the process of assimilating historical knowledge, we note that the methods proposed by the authors really make it possible to actualize such knowledge, filling the student audience with sharp discussions and developing students' freedom of scientific thinking.

\section{MATERIALS AND METHODS}

The authors of the study offered to your attention, having many years of total experience in teaching social disciplines (history, political science, sociology, cultural studies), have repeatedly tested various innovative teaching methods. At the same time, the study of the listed disciplines was carried out both in historical specialties and in other specialties, including humanitarian, natural science, technical, etc. It is this rich and diverse empirical experience that allowed us to carry out a certain selection of the most successful, in our opinion, forms of education.

It should be noted that the accumulation of empirical material took place directly in the course of several stages of reforming the entire system of higher education in Russia. In particular, the educational standard for the absolute majority of training profiles has been repeatedly changed, containing a set of basic requirements for the level of training of graduates. The content of the latest versions of such standards today directly indicates the need to use innovative technologies in Russian higher educational institutions that can develop students' abilities for self-education, high motivation for independent creative activity, and a culture of research scientific work. Such requirements fully coincide with the aim of the authors of the article to achieve high efficiency of learning outcomes.

Considering the fact that the authors of the study taught a significant number of subjects of a social orientation, it is primarily of an interdisciplinary nature. For each individual discipline, the teaching methodology has its own specific features, however, the general direction of its development for us during the last period of time has remained the same. Therefore, the summing up of the intermediate results described below was the result of a systematic approach, which made it possible to develop certain general requirements and recommendations.

The methodological basis of the study was also made up of anthropological and sociocultural approaches. 
The first of them is based on the personal character of modern education both in the higher education system and in secondary school. Taking into account the personality traits of a student has become the most important requirement for the content and form of education, manifested in the basic principle of humanization of education. The application of the sociocultural approach has become a necessary element of the study due to the fact that the change in the methodological and methodical component of the teaching process of social disciplines is, among other things, the result of permanent global changes in the social structure and content of modern culture.

At the same time, among the fundamental principles of studying social disciplines in a modern higher educational institution, we include the continuity, succession, integrability and openness of education, as well as its creative, research nature. In the direct practice of students' educational activities, they should be reflected in the use of active interactive forms of learning, as well as online technologies, which are especially in demand today.

It should also be noted that such a significant methodological experience of the authors of the proposed study described above was reflected in more than 30 publications published over the past twenty years and devoted to the problem of applying innovative methods in the teaching of social sciences $[1 ; 10 ; 11 ; 12 ; 13$; $15 ; 16$ and others].

\section{RESULTS}

The initial stage of modernization of the system of teaching social sciences in modern Russian society was determined by two contradictory processes: the integration of Russia into the world community and, on the other hand, the search for a national idea, an increased interest in the development of national cultures. Both of these tendencies were reflected primarily in the content of school teaching, and then in the system of higher educational institutions, intending"History" as a general course ofstudyin non-core specialties.

The first tendency is manifested in the problem of correlation between world and Russian history in the content of teaching. Back in the 19th century, two practically independent linear historical courses developed in the Russian educational system: the history of the Russia and the history of foreign countries. The principle of unsynchronized alternation of periods in the study of Russian and foreign history, teaching of simultaneous events in different classes led to a different-scale perception of similar processes in world and national history, a difference in terminology, conceptual approaches, etc.

The relevance and complexity of solving the problem of the correlation between teaching general and national history lies in several tasks.

First, there is a need to correlate the patriotic tasks of historical education with the need for a world-historical approach. Domestic history, undoubtedly, should prevail in the coverage of certain general and specific patterns and in the preservation of a larger number of academic hours allocated for its study, but without breaking the synchronicity in teaching, without retouching national history.

The second task is to form the ability to present in chronological order the phenomena that took place in different countries of the progressive cultural world, to create a holistic picture of world history.

And the third task is the further development of a civilizational approach to the study of history, which requires more attention to cultural, religious, ecological problems of universal human significance; the ability to correlate the national identity of local civilizations and common milestones in world history.

With regard to this third task, it should be noted that in the history teaching curriculum in our country, for a long period, the component of the correlation between Russian and national-regional history has remained insufficiently developed. In a number of republics of the Russian Federation, regional history is still taught as the history of the titular nation, despite the multi-ethnic character of the region.

A definite way out of the described situation was the introduction of the training course "My City", designed to be studied in grades 5-9 in schools of the city of Cheboksary in 2000. [2; 3] When distributing the material among the classes, the age characteristics of the students, the parallelism of study with the general courses of world and Russian history, geography, the culture of the native land, and the foundations of legal knowledge were taken into account. The work which was begun at that time continues to this day. [10, 148153] In 2020, the school curriculum for 8th grade students in Cheboksary includes a new textbook "My City", developed by the former team of authors. Of particular interest to it is the form of presentation of educational material on the principle of historical short stories. [4]

Nevertheless, on the whole, the existing correlation of world, Russian and regional history in teaching at school and university (for non-historical specialties) remains problematic. The problem of creating an 
integrated, strictly synchronized course of history, containing objective assessments of the interdependence of nations and the contribution of various civilizations to the single world history, remains relevant.

Another necessary, in our opinion, principle of studying the social sciences in general is the observance of their integrability and continuity. The totality of the social sciences is precisely a system of humanitarian knowledge, while the elements of the system must have the ability to interpenetration and diffusion.

An example is the change in approaches in the field of legal education. The need for legal education of young people in modern Russia is beyond doubt. At the same time, legal education provides not only legal literacy, but, first of all, the formation of a certain level of legal culture. Legal culture lies in persistent ideological convictions and in a certain way of life and behavior. Of course, these skills in the younger generation cannot appear only as a result of studying even the most perfect course in jurisprudence. The most important principles of legal education should be the principles of continuity and succession. Legal education should begin in preschool institutions, continue at school and improve at the university.

The principle of the continuity of legal education does not imply the obligatory allocation of special hours in the curriculum. Ample opportunities for legal education are provided by subjects of the humanitarian cycle. Of particular difficulty is the observance of the principle of continuity of legal education during the transition of a student from school to a higher educational institution. In this case, continuity implies the succession of the main content of legal education in all educational institutions. The difficult transition for a young person from schoolchildren to student status is often accompanied by a reassessment of basic moral criteria. Therefore, it is especially important to continue work on legal education. However, the curriculum of non-law faculties of higher education provides only a small course in law. In practice, with the existing richness of curricula, this deficiency can be filled only in conditions of compliance with another basic principle of social sciences - their integrability and consistency. Legal topics should be reflected in the content of training courses in history, political science, sociology, cultural studies. In turn, knowledge in the field of these humanitarian disciplines should be replenished within the framework of other academic subjects that make up a common integrated system.

In the practice of studying individual social sciences in higher educational institutions, the implementation of the principles described above is possible primarily through the use of innovative teaching methods. Their main advantage lies in the transition from passive to active forms of learning. This goes well with the orientation of the university program towards independent types of work, which provide not only the assimilation of facts, but also the knowledge of the historical process, the development of creative, research and critical thinking.

For a number of years we have been actively using various innovative teaching methods in our practice. These are forms of educational and play, modeling activities (for example, reconstruction games "The Court of Salic Truth", "Meeting of the Pilgrims in Rome on Christmas Day 1300"; role-playing games, tests and colloquia in the form of quiz games, etc.) ...

An important aspect of innovative methods is the organization of training as a creative discussion, an active exchange of views (in the form of "debates", "round table", "court session", etc.).

In organizing the educational and scientific work of students, we came to the conclusion that it is advisable to formulate the topics of coursework and examinations, as well as examination questions in the form of historical tasks or, more precisely, problem questions.

Even traditional lecture classes can become much more effective if the lecture material is structured in the form of a problematic problem or a lecture with elements of a supporting summary.

New approaches to teaching require new forms of organization of the educational process. This primarily concerns the need to improve pedagogical control. In many foreign and a number of Russian higher educational institutions, a rating system for assessing knowledge is successfully used, which allows to accurately determine both the indicator (rating) of a particular student in point measurement, and his place in this group of students (from the first "student" to the most careless). The rating takes into account various criteria for assessing knowledge, skills, and abilities.

The use of the rating system implies the restructuring of the teaching technology using blocks or modules. The essence of modular training consists in dividing the course into logically completed blocks, while maintaining continuity between blocks and the integrity of the overall concept of the course.

We assess the work of students according to several parameters. The first is the skills of working with sources, work in seminars and practical classes. The topics of the individual lessons are combined into large 
blocks for which each student must receive a credit. The basis for the credit is not only a speech on a particular issue. For participation in the discussion, additions and even interesting questions, one or more points are awarded, which are summed up in the credit score according to the results of the lessons of this block. Students who are passively present, absent and received unsatisfactory marks write independent written works or answer test assignments on the topic of this block. All block scores are summed up and represent one of the components of the rating score.

The second parameter by which the rating is determined is the presentation of the report. The assessment of the report is the prerogative of not only the teacher, but also of all students and is the arithmetic mean of the assessments of all students. Students put their marks in the course of an oral discussion of the report or in the form of a written review. At the end of the semester, a competition of the reports heard is held. The author of the best report receives additional points to the overall rating score.

The third parameter is the preparation of written abstracts, tests, the topics of which are formulated as a task or problem. For example: "Why did the uprising of Wat Tyler contribute to the personal emancipation of the peasants, and the uprising of Gyord Doji to enslave the peasantry?" or "How did the fate of Jan Huss influence the fate of Martin Luther?" etc.

During the semester, test control over the knowledge of students is constantly carried out. In this case, the final exam is carried out orally. The exam questions are formulated in the form of historical tasks ("compare", "prove", "why", etc.).

When passing the oral exam, the overall rating score is also taken into account. Students are conventionally divided into three main groups. Those with a rating score close to the group's average rating score pass the exam in the usual form. Students with the highest ranking score receive an additional point towards the exam score. Students with a low rating score additionally answer a small test program.

The use of several variants of pre-prepared test papers instead of additional questions on the exam allows avoiding controversial situations when putting exam marks. According to our observations, the use of the rating system significantly increases the activity of students, contributes to the emergence of healthy competition among them, the systematic nature of their studies and, in general, allows an objective assessment of the work of each student.

In addition, in the use of the rating system, another basic principle of modern higher education is maximally observed - its openness, based on the accessibility, variability and individualization of the teaching process. If this principle is observed, it becomes inevitable to shift the focus from classroom teaching to students' independent work.

In the last period of time, the use of the possibilities of open online courses has become another form of organizing students' independent work. Online learning in the process of formal education is becoming more and more popular. In this regard, only the authors of this article have more than 5 different online courses that have arisen during 2019-2020 at different stages of development. Of course, the introduction of digital technologies into the educational process has a number of difficulties and disadvantages, but now it is already clear that this form of education has a right to exist, providing the student with the opportunity to make a final independent choice. Among the main problems in organizing such a form of training, the researchers attribute the difficulty of providing feedback at lectures, the uniformity of practical classes, the provision of the necessary equipment and social isolation of students. [12, 194-196] However, the advantages of using online learning are also significant. First of all, this is mobility and variability, the possibility of attracting highly qualified narrow-profile specialists who do not work in this educational institution. Taking into account that the trend of including various formats of online learning in the curricula of educational programs is global, it should be assumed that they will be increasingly used at the level of regional higher educational institutions.

\section{DISCUSSION AND CONCLUSION}

The problems we have named for the further development of the methodology and methods of teaching the social sciences are a constant subject of discussion among specialists at both the regional and national levels.

At the same time, for example, the very formulation of the question of synchronous teaching of history among teachers does not raise any particular objections. The difficulty lies in its practical implementation: the development of principles for building such a course, the creation of theoretically and methodologically grounded programs and teaching aids. In this respect, it is useful to study the history of the problem. Attempts to create synchronized courses in general and national history have been made in our country 
more than once. Attention is drawn to the interesting fact that these reforms in education have always coincided with the periods of liberalization of the country's life, with the desire to get closer to the ideals of Western civilization.

Simultaneously with the internationalization of the culture of modern Russian society, there is an increased interest in Russian national history. At the same time, calls are increasingly being heard to expand the role of history education in the patriotic education of youth. The problem of patriotic education is undoubtedly one of the most important in modern Russia. However, there is a fear that love for the Motherland can turn history into an instrument of ideology, and this, unfortunately, has been observed in our country many times.

When developing new content for training courses in the field of social knowledge, the experience of foreign colleagues should also be taken into account. For example, the problem of the relationship between the teaching of national and world history in different countries has repeatedly been the subject of close attention of the Council of Europe. On his initiative, a number of conferences and symposia were held on the topic of teaching history in schools. Back in 1997, the secretariat of the Council of Europe made the following recommendations: "Textbooks should represent a true balance of local, regional, national, European and world history and geography." [15, 91]

At that time, Council of Europe experts drew attention to the fact that in many European history textbooks the main goal was the formation of a national idea. For example, G. Steiner-Hansi noted that "history is a powerful means of uniting and dividing peoples, making them friends or enemies, promoting social peace, or, conversely, reigning chaos." $\mathrm{V}$. Hepken believes that "it is necessary for textbooks to offer an integrative and pluralistic concept of identity within the framework of a multinational state". [6, 12-19]

The question of the constant increase in the proportion of students' independent work in the curricula remains debatable, which, according to a number of colleagues, causes a serious imbalance in the ratio of the content of the lecture course and practical classes. [17, 81] Given the lack of practical skills of independent research work in a certain category of students who need increased supervision from the teacher, this can indeed be a significant problem in terms of consolidating knowledge in the field of social sciences. However, it is in this component of educational activity that the use of online technologies may help.

In any case, it is only possible to count on ultimate success in teaching social sciences in modern higher education through the use of innovative approaches. It is their systemic integrated application, the use of constantly changing combinations of forms and methods, while taking into account their individual advantages and also a specific contingent of students with their individual qualities, that will ultimately achieve a high degree of efficiency.

\section{REFERENCE LIST}

1) Ageeva N.N. (2017). S.F. Fortunatov on the problems of teaching history in gymnasiums. Topical issues of archeology, ethnography, history (collection of articles), Cheboksary, p. 92-95.

2) Danilova A.P., Danilov V.D., Ivanova T.N. (2000). My city (Travel to Cheboksary).An experimental textbook for grade 5.Cheboksary, $155 \mathrm{p}$.

3) Danilova A.P., Danilov V.D., Ivanova T.N. (2001). My city (25 questions on the early history of Cheboksary).An experimental textbook for grades 6-7.Cheboksary, $128 \mathrm{p}$.

4) Danilova A.P., Ivanova T.N., Danilov V.D. (2020). My city. Historical short stories about Cheboksary of the 18th century. Textbook for grade 8 . Cheboksary.

5) Fallace T., Neem J. (2005). Historiographical Thinking: Towards a New Approach to Preparing History Teachers. Theory and Research in Social Education, vol. 33, issue 3, p. 329-346. https://doi.org/10.1080/00933104.2005.10473285

6) Gallagher K. (1996). Teaching history and promoting democratic values and the idea of tolerance. Strasbourg.

7) Gestsdóttir S.M., van Boxtel C., van Drie J. (2018). Teaching historical thinking and reasoning: Construction of an observation instrument. British Educational Research Journal, vol. 44 (6), p. $960-$ 981. 
https://doi.org/10.1002/beri.3471

8) Goldberg T. (2013). It's in My Veins: Identity and Disciplinary Practice in Students' Discussions of a Historical Issue. Theory \& Research in Social Education, vol. 41: 1, p. 33-64. https://doi.org/10.1080/00933104.2012.757265

9) Goldberg T., Schwarz, Baruch B. and Porat D. (2011). "Could They Do It Differently?": Narrative and Argumentative Changes in Students 'Writing Following Discussion of "Hot" Historical Issues'. Cognition and Instruction, vol. 29: 2, p. 185 - 217.

https://doi.org/10.1080/07370008.2011.556832

10) Ivanova T.N., Myagkov G.P. (2020) History of the Native Territory in school textbooks: educational and upbringing potential, Development of the Chuvash statehood in the context of Russian federalism: past, present, future (collection of articles). Cheboksary, p. 147-155.

11) Ivanova T.N. (2016). Formation of research skills of bachelor students in the process of teaching the discipline "History of the Middle Ages", Teacher of history in the socio-cultural space of Eurasia in the late XX - early XXI century. (Digest of articles). Kazan, p. 340-345.

12) Krasnova M.N., Idrisov R.A. (2019). Digital technologies in preparation for the Unified State Exam in Social Studies, Experience of an educational organization in the formation of digital skills (collection of articles). Cheboksary, p. 290-292.

13) Krasnova M.N., Shirokov O.N., Kornyakova K.N. (2020). Online education in modern conditions: problems and prospects, Digital transformation of modern education (collection of articles). Cheboksary, p. 193-197.

14) Lewthwaite S., Nind M. (2016). Teaching Research Methods in the Social Sciences: Expert Perspectives on Pedagogy and Practice. British Journal of Educational Studies, vol. 64: 4, p. 413-430. https://doi.org/10.1080/00071005.2016.1197882

15) Low-Beer E. (1997). Council of Europe and history at school. Strasbourg.

16) Shirokov O.N., Idrisov R.A., Yakovleva T.V. (2018). Modern University as an Organizer of Innovation, Problems of Education, History and Culture through the Prism of Russia's Ethnic Diversity (collection of articles). Cheboksary, p. 365-367.

17) Suslov A.Yu., Salimgareev M.V., Khammatov Sh.S. (2017). Innovative methods of teaching history in a modern university. The Education and Science Journal, vol. 19, issue 9, p. 70-85.

https://doi.org/10.17853/1994-5639-2017-9-70-85

18) Wansink B., Akkerman S., Wubbels T. (2017). Topic variability and criteria in interpretational history teaching. Journal of Curriculum Studies, vol. 49: 5, p. 640-662.

http://dx.doi.org/10.1080/00220272.2016.1238107 